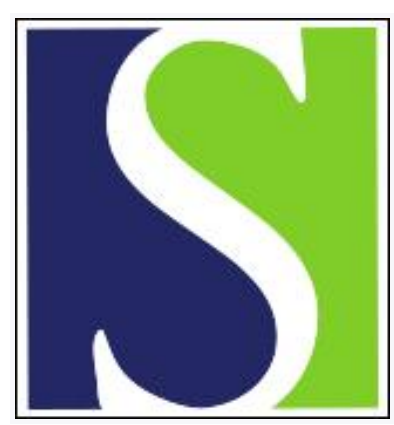

Scand J Work Environ Health 1998;24(5):351-357

https://doi.org/10.5271/sjweh.355

Issue date: Oct 1998

Joint effect of shift work and adverse life-style factors on the risk of coronary heart disease

by Tenkanen L, Sjöblom T, Härmä M

The following articles refer to this text: 2001;27(3):161-213;

2002;28(1):64-71; 2008;34(1):33-39; 2009;35(1):48-55;

2009;35(3):157-161

Key terms: circadian rhythm; interaction; obesity; physical activity; smoking; thrombosis

This article in PubMed: www.ncbi.nlm.nih.gov/pubmed/9869306 


\title{
Joint effect of shift work and adverse life-style factors on the risk of coronary heart disease
}

\author{
by Leena Tenkanen, PhD, ${ }^{1}$ Tom Sjöblom, MD, ${ }^{2}$ Mikko Härmä, $M D^{3}$
}

\begin{abstract}
Tenkanen L, Sjöblom T, Härmä M. Joint effect of shift work and adverse life-style factors on the risk of coronary heart disease. Scand J Work Environ Health 1998;24(5):351-357.

Objectives The joint effect of shift work and certain adverse life-style factors on coronary heart disease (CHD) was studied.

Methods Base-line measurements were obtained for a 6-year follow-up of an industrially employed cohort $(\mathrm{N}=1806$ ), whose shiftwork status was recorded from a questionnaire filled out by a sample of the cohort. The CHD end points (codes 410-414 of the 9th revision of the International Classification of Diseases) were obtained from official Finnish registers. In order that the joint effects of shift work and life-style factors on the risk of CHD could be studied, dichotomized variables and their combinations as a dummy variable system in Cox's proportional hazards models were used.

Results The relative risks were $1,1.6$ [95\% confidence interval (95\% CI) $1.1-2.5], 1.3(95 \% \mathrm{CI} 0.9-2.1)$, and 2.7 (95\% CI 1.8 - 4.1) for the following combinations of shift work (SW) and smoking (SM): SW-\&SM-, SW$\& \mathrm{SM}+, \mathrm{SW}+\& \mathrm{SM}-$, and SW+\&SM+, respectively; and the corresponding figures for shift work and obesity (BMI $\geq 28 \mathrm{~kg} / \mathrm{m}^{2}$ ) were $1,1.2(95 \% \mathrm{CI} 0.8-1.9), 1.3(95 \% \mathrm{Cl} 0.9-1.9)$, and $2.3(95 \% \mathrm{CI} 1.5-3.6)$, respectively. In both cases the effect was at least multiplicative. For the shift workers the relative risk for CHD rose gradually with increasing numbers of adverse life-style factors, but for the day workers there was no clear dose-response pattern. Conclusions Shift work seems to trigger the effect of other, lifestyle-related risk factors of CHD and therefore calls for active prevention among shift workers.
\end{abstract}

Key terms circadian rhythm, interaction, obesity, physical activity, smoking, thrombosis.

The question of whether or not shift work is associated with coronary heart disease (CHD) has been studied since the middle of the century. While the early studies were mostly inconclusive or even negative (1), later prospective studies have repeatedly shown a positive association between shift work and $\mathrm{CHD}(2-5)$. Although these studies have now established shift work as a risk factor for CHD, many problems still remain. In their classical paper Fox \& Adelstein (6) posed the question "Work or way of life?" Today, it seems more relevant to formulate it thus: "Work and way of life jointly?" In cancer research there are numerous studies on the joint effects of various occupational exposures and, for instance, smoking, the most important of the adverse life-style factors (7). There exist as yet no such studies in the context of shift work, life-style, and CHD, although such studies would be important from a preventive point of view (8).
Smoking is a classical risk factor for CHD, with several pathways for its effect $(9,10)$. Little physical activity during leisure time is another established CHD risk factor for men $(11-13)$. Obesity is associated with several risk factors for CHD. First, it predisposes to increasing levels of insulin resistance (14-15), and, second, either as a consequence or independently, it is associated with an unfavorable lipid profile, hypertension, and decreased fibrinolytic capacity $(16,17)$. All these lifestyle factors are fairly commonly found, and they are often found in clusters.

In our previous paper on the CHD risk associated with shift work among industrially employed Finnish men, we showed that shift work was associated with a $30-50 \%$ excess risk of CHD and that the risk could not be entirely explained by differences in life-style factors, total serum cholesterol, or high-density lipoprotein (HDL)

1 Helsinki Heart Study, Helsinki, Finland.

2 School of Public Health, University of Tampere, Tampere, Finland.

3 Finnish Institute of Occupational Health, Helsinki, Finland.

Reprint requests to: Dr Leena Tenkanen, Helsinki Heart Study, Kalliolinnantie 4, FIN-00140 Helsinki, Finland. [E-mail: Leena.Tenkanen@ktl.fi] 
cholesterol among shift workers and day workers (4). This result does not mean that the life-style factors are of no importance in the assessment - and prevention of CHD risk among shift workers. The present work is a continuation of our previous research, and its aim was to study the joint effects of shift work and the life-style factors smoking, obesity, and lack of leisure-time physical activity on the risk of CHD through the use of data collected in the Helsinki Heart Study.

\section{Subjects and methods}

\section{Study population and the follow-up}

The subjects were selected from among the participants of the first screening visit for the Helsinki Heart Study, a 5-year, placebo-controlled coronary prevention trial with middle-aged men ( $40-55$ years of age at entry) (18). The participants for the trial were selected via successive screenings at 2 government agencies and 5 industrial companies. The industrial cohort comprised men working in oil refineries, the wood-processing industry (paper, sawmill, plywood) and heavy engineering. The volunteers were eligible for the trial if their serum nonhigh-density lipoprotein cholesterol was $\geq 5.2 \mathrm{mmol} / \mathrm{l}$ in both pretreatment screenings and if they had no evidence of CHD or any other major illness.

In the present follow-up cohort, only participants employed in industry were included. The subjects came from different selection phases of the Helsinki Heart Study; this procedure was followed to ensure that the subjects were representative of the source population. First, a reference group was selected by systematic sampling from among the people who did not fulfill the selection criteria in the first screening. Second, all those who did fulfill the criteria in the first screening, but not in the second, were chosen as a second reference group. After the double blind trial phase, the treatment group was revealed to the participants, and its members were allowed to choose whether or not they wanted to continue with the medication (gemfibrozil group) or whether to begin with it (placebo group). At the end of the double blind trial in 1986 - 1987, a psychosocial questionnaire was also mailed to those in the intervention and reference groups. The response rate was $70 \%(\mathrm{~N}=1947)$ for the industrial group. Of these $38 \%$ belonged to the reference groups that had never been on gemfibrozil, $16 \%$ belonged to either of the trial groups, but did not continue on medication, and $46 \%$ belonged to one of the trial groups and chose to continue (or start) medication. After the exclusion of those with missing information on occupation or shiftwork status and a small group of parttime workers, the study group comprised 1806 men.

Our follow-up lasted from the administration of the questionnaire to the end of 1993, with a mean follow-up time of 5.6 years. The end points were obtained from the Hospital Discharge Register and the Register of Deaths kept by Statistics Finland. Several studies have found these registers to be accurate enough for epidemiologic purposes in studies of CHD (19). In accordance with our previous study (20), our definition of CHD was based on codes $410-414$ of the International Classification of Diseases, 9 th revision.

\section{Occupation and shiftwork status}

We used broad occupational categories in our study, but the information was based on the 3-digit occupational code used in the 1980 census - a Finnish version of the Nordic Classification of Occupations from 1965. This information was obtained by record linkage with Statistics Finland. In the analyses, occupation was used as a dichotomized variable: white-collar workers (academic and clerical) versus blue-collar industrial workers. The latter group comprised the occupational categories of iron and metalware work, machine work in plants, woodworking, and chemical process work.

Shift work was recorded in the questionnaire on the following 6-point scale: 1 = day work, 2 = part-time work, 3 =2-shift work, $4=3$-shift work, 5 = irregular work, and $6=$ night work. In the analyses a dichotomized variable was used ( 1 = day work, 2 = shift work, all combined). The 14 men working part-time were excluded.

In this industrial study population, $71 \%$ of the participants were blue-collar workers. Among the blue-collar workers, $48 \%$ were shift workers, compared with only $9 \%$ of the white-collar workers. Most of the participants in the shiftwork groups had held their jobs for more than 5 years.

\section{Life-style factors}

All the life-style factors used in our study were recorded at the first screening visit in 1982. In the interview, smoking habits were recorded on a 7-point scale taking into account the number of cigarettes smoked and the time at which the respondent had given up smoking. We then used a dichotomized variable (0 for never or past smoking and 1 for current smoking) in our study. Leisure-time physical activity was recorded with the 4-point Gothenburg scale (21), but a dichotomized variable was used in the analyses. Body mass index was calculated as weight in kilograms per square meter of height.

\section{Blood pressure and serum lipids}

Blood pressure was recorded from the right arm during the first screening visit, with calibrated mercury sphygmomanometers with cuffs measuring $12 \times 40 \mathrm{~cm}$. The measurement was carried out in a sitting position before the blood sample was taken. The lipid measurements in this lipid modulation trial have been described in detail elsewhere (18). 


\section{Statistical methods}

To study the joint effects of shift work and the different life-style factors, we first formed a new variable on the basis of the dichotomized variables to represent different combinations of the risk factor levels, as is usual in experimental design. In the case of shift work (SW) and obesity (BMI), for instance, the study population was divided into the following groups by using a grouping variable: SW-\&BMI-, SW-\&BMI+, SW+\&BMI-, $\mathrm{SW}+\& \mathrm{BMI}+$. The relative risks (RR) of CHD among those belonging to the last 3 groups in comparison with the 1 st (nonobese day workers) were then estimated using Cox proportional hazards models (22). With this approach, the statistical interaction term is implicitly included in the model and serves as a correction of the model. Such correction would be needed if the initial assumption of a multiplicative joint effect of smoking and obesity did not prove to be appropriate. When the risks were estimated according to the given description, we were able to see immediately how far or close the effect was from multiplicative.

\section{Results}

We first explored the overall CHD risk associated with the life-style factors by analyzing simultaneously the effects of shift work, smoking, obesity, and sedentary lifestyle (table 1). Both smoking and obesity were significant risk factors if only age was adjusted for, but, if total serum cholesterol and HDL cholesterol were added to the model, the risk estimate for obesity dropped considerably. In contrast, the estimate for CHD risk associated with shift work was not altered whether or not total cholesterol and HDL cholesterol were added as covariates. (This finding suggests that the effect of shift work does not operate via serum lipid levels, while that of obesity does.) When analyzed simultaneously with the other lifestyle factors, the effect of sedentary life-style appeared to be marginal.
Figure 1 shows the joint effects of shift work and different life-style factors in terms of the crude incidences of CHD. Shift work enhanced the adverse effect of the life-style factors on CHD risk; in the case of smoking and obesity, the joint effect was at least multiplicative. This impression was confirmed when the relative risks of the joint effects were modeled (table 2). Even sedentary life-style, when combined with shift work, entailed an $87 \%$ excess risk $(\mathrm{P}<0.02)$ in a comparison with physically active day workers, and the risk due to smoking was strongly accentuated among shift workers. If total cholesterol and HDL cholesterol were added as covariates, the risk patterns were flattened, as could be expected. The flattening effect of HDL cholesterol exceeded that of total cholesterol (results not shown). When comparing the joint effect of shift work and increasing numbers of adverse life-style factors on CHD risk (figure 2, table 3), we clearly saw how shift work enhanced the CHD risk due to adverse life-style. While among day workers those with $2-3$ adverse life-style factors had about twice the risk of those with no such factors, among

Table 1. Shift work and life-style factors as simultaneous predictors of coronary heart disease (CHD) risk among industrially employed men. The relative risks (RR) with $95 \%$ confidence intervals $(95 \% \mathrm{Cl})$ were derived using Cox proportional hazards models with different covariates. (Tot $C=$ total serum cholesterol, $\mathrm{HDLC}=$ high-density lipoprotein cholesterol, BMI = body mass index)

\begin{tabular}{llllll}
\hline Risk group $\begin{array}{l}\text { Reference } \\
\text { group }\end{array}$ & \multicolumn{5}{c}{ Relative risk } \\
\cline { 3 - 6 } & & $\begin{array}{c}\text { Age- } \\
\text { adjusted }\end{array}$ & $95 \% \mathrm{Cl}^{\mathrm{a}}$ & $\begin{array}{c}\text { Age-Tot } \\
\text { C-HDLC- } \\
\text { adjusted }\end{array}$ & $95 \% \mathrm{Cl}^{\mathrm{b}}$ \\
\hline $\begin{array}{l}\text { Shift work } \\
\text { Smoking }\end{array}$ & $\begin{array}{l}\text { Day work } \\
\text { Non or past } \\
\text { smoking }\end{array}$ & 1.46 & $1.07-2.00$ & 1.48 & $1.08-2.03$ \\
Sedentary & $\begin{array}{l}\text { Physically } \\
\text { active }\end{array}$ & 1.76 & $1.28-2.42$ & 1.52 & $1.10-2.10$ \\
Obese (BMI BM! & $0.77-1.51$ & 1.00 & $0.71-1.40$ \\
$\left.\geq 28 \mathrm{~kg} / \mathrm{m}^{2}\right)$ & $<28 \mathrm{~kg} / \mathrm{m}^{2}$ & 1.45 & $1.05-2.02$ & 1.14 & $0.82-1.60$ \\
\hline $\begin{array}{l}\text { a For age-adjusted RR. } \\
\text { b For age-Tot C-HDLC-adjusted RR. }\end{array}$ & & & & \\
\hline
\end{tabular}
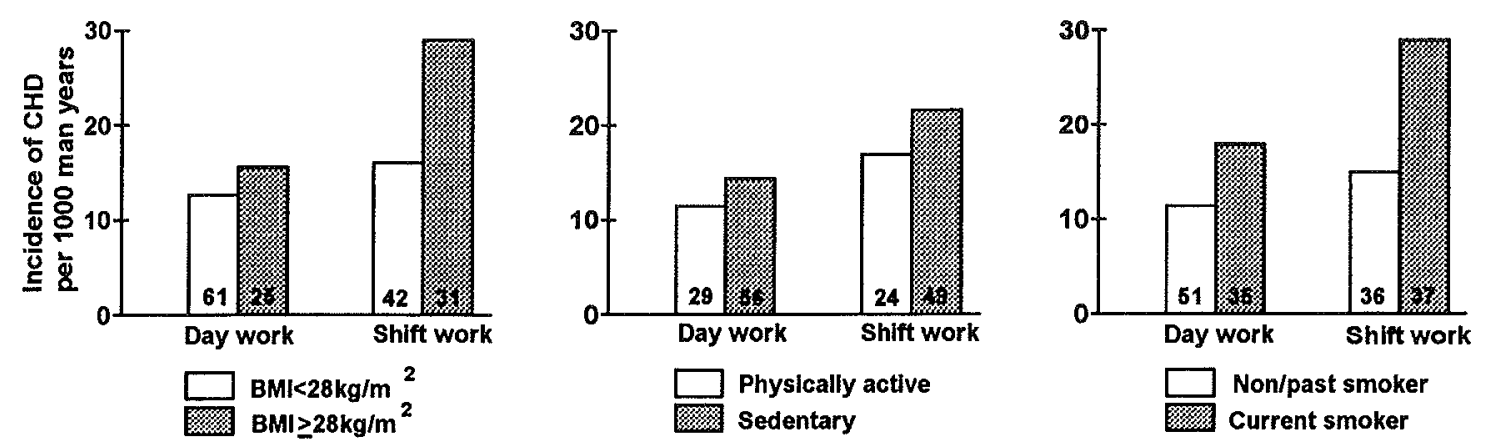

Figure 1. Crude incidences of coronary heart disease (CHD) by shiftwork status and the life-style factors obesity (BMI=body mass index), sedentary life-style, and smoking. The number of CHD cases in each category is given at the foot of the corresponding bar. 
Table 2. Joint effect of shift work and some life-style factors on the risk of coronary heart disease among industrially employed men. The relative risks with $95 \%$ confidence intervals were derived via Cox proportional hazards models with age as a covariate. ( $\mathrm{RR}=$ relative risk, $95 \% \mathrm{Cl}=95 \%$ confidence interval, $\mathrm{BMI}=$ body mass index)

\begin{tabular}{lrc}
\hline Life-style factor & $\mathrm{RR}$ & \multicolumn{1}{c}{$95 \% \mathrm{Cl}$} \\
\hline Smoking & & \\
$\quad$ Day work \\
$\quad$ Non or past smoker & 1 & \\
$\quad$ Smoker & 1.61 & $1.05-2.48$ \\
Shift work & & \\
$\quad$ Non or past smoker & 1.34 & $0.88-2.06$ \\
$\quad$ Smoker & 2.69 & $1.76-4.12$ \\
Leisure-time physical activity & & \\
Day work & & \\
$\quad$ Physically active & 1 & \\
$\quad$ Sedentary & 1.19 & $0.76-1.85$ \\
Shift work & & \\
$\quad$ Physically active & 1.42 & $0.83-2.42$ \\
$\quad$ Sedentary & 1.87 & $1.19-2.94$ \\
Obesity & & \\
Day work & & \\
BMI $<28 \mathrm{~kg} / \mathrm{m}^{2}$ & 1 & \\
BMI $\geq 28 \mathrm{~kg} / \mathrm{m}^{2}$ & 1.19 & $0.75-1.90$ \\
Shift work & & \\
BMI $<28 \mathrm{~kg} / \mathrm{m}^{2}$ & 1.29 & $0.87-1.91$ \\
BMI $\geq 28 \mathrm{~kg} / \mathrm{m}^{2}$ & 2.32 & $1.50-3.57$ \\
\hline
\end{tabular}

shift workers the corresponding relative risk was more than 3 (table 3 ). The accumulation of adverse life-style factors was reflected in the levels of serum lipids in that the HDL cholesterol levels decreased and triglyceride levels increased as the number of life-style factors increased (table 4). The changes were, however, similar among the day and shift workers.

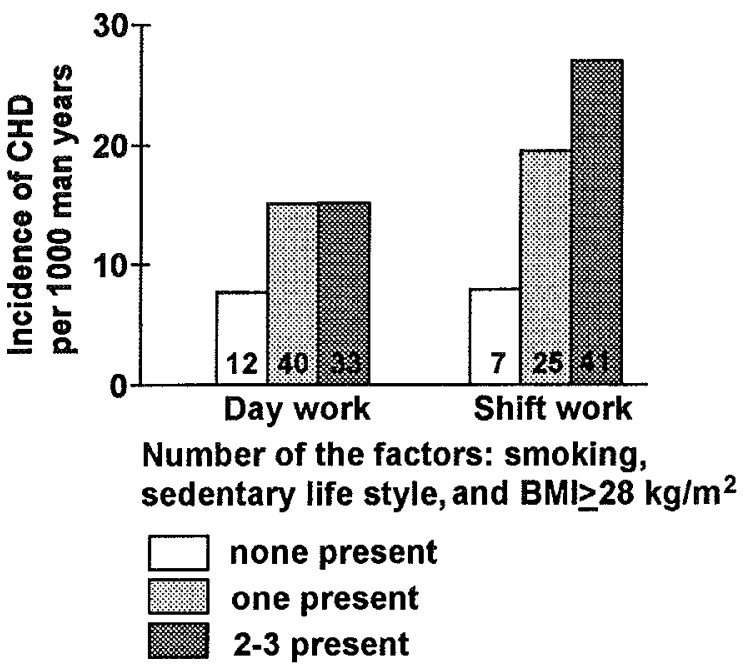

Figure 2. Crude incidences of coronary heart disease (CHD) by shiftwork status and level of accumulation of the factors smoking, sedentary life-style, and obesity. The number of CHD cases in each category is given at the foot of the corresponding bar.
These analyses where based on data from the entire population of industrially employed men, and consequently a higher proportion of the white-collar workers were day workers than shift workers. To control for potential confounding by occupational group, we repeated the analyses using only blue-collar workers, although the group of day workers was thereby considerably decreased. The risk pattern among the shift workers was closely similar to the one we have presented in this report, while for the day workers the confidence intervals were larger and the results were less conclusive. Nevertheless, the principal results remained the same.

\section{Discussion}

Our main finding was that shift work persistently accentuated the CHD risk associated with the adverse life-style factors smoking, sedentary life-style and obesity, the joint effect being at least multiplicative. The overall average effect of shift work on CHD risk was of the same magnitude as the effect of belonging to a group with a body mass index of $>28 \mathrm{~kg} / \mathrm{m}^{2}$, but clearly lower than, for example, the CHD risk due to smoking. However, although the dichotomized variables used for the life-style factors were fairly crude instruments for the assessment of CHD risk, a clear dose-response relationship emerged between the degree of clustering of these factors and the risk of CHD among shift workers, but not among day workers.

\section{Model considerations}

A multiplicative effect of the risk factors included in this study was the basic assumption when risks were modeled using the Cox model or any similar approach. If, in reality, the effect of the risk factors is less than multiplicative, for example, additive, or more than multiplicative, then an interaction term can be added to the model

Table 3. Joint effect of shift work and the number of adverse life-style factors [smoking, sedentary life-style, obesity (body mass index $\left.\left.\geq 28 \mathrm{~kg} / \mathrm{m}^{2}\right)\right]$ on the risk of coronary heart disease (CHD) among industrially employed men. The relative risks with $95 \%$ confidence intervals were derived via Cox proportional hazards models with age as a covariate. $(\mathrm{RR}=$ relative risk, $95 \% \mathrm{Cl}=$ confidence interval)

\begin{tabular}{lrr}
\hline Shiftwork status & RR & $95 \% \mathrm{Cl}$ \\
\hline Day work & & \\
0 factors present & 1 & \\
1 factors present & 1.98 & $1.04-3.77$ \\
$2-3$ factors present & 1.92 & $0.99-3.71$ \\
Shift work & & \\
0 factors present & 1.04 & $0.41-2.63$ \\
1 factors present & 2.54 & $1.27-5.05$ \\
2 -3 factors present & 3.62 & $1.90-6.90$ \\
\hline
\end{tabular}


Table 4. Base-line levels of total serum cholesterol (TotC), high-density lipoprotein cholesterol (HDLC) and triglycerides (TG) in categories of shiftwork status and the number of adverse life-style factors present, smoking, sedentary life-style, obesity (body mass index $\left.\geq 28 \mathrm{~kg} / \mathrm{m}^{2}\right)$. $^{\mathrm{a}}$

\begin{tabular}{|c|c|c|c|c|c|c|c|c|}
\hline \multirow[t]{3}{*}{ Shiftwork status } & & \multicolumn{4}{|c|}{ Entire cohort } & \multicolumn{3}{|c|}{ Intervention groupa } \\
\hline & \multirow{2}{*}{$\begin{array}{c}\text { Number of } \\
\text { subjects }\end{array}$} & \multicolumn{2}{|c|}{ TotC $(\mathrm{mmol} / \mathrm{l})$} & \multicolumn{2}{|c|}{ HDLC (mmol/l) } & \multirow{2}{*}{$\begin{array}{l}\text { Number of } \\
\text { subjects }\end{array}$} & \multicolumn{2}{|c|}{ TG (mmol/l) } \\
\hline & & Mean & SD & Mean & $\mathrm{SD}$ & & Mean & SD \\
\hline \multicolumn{9}{|l|}{ Day work } \\
\hline $\begin{array}{l}0 \text { factors present } \\
1 \text { factors present } \\
2-3 \text { factors present }\end{array}$ & $\begin{array}{l}275 \\
476 \\
387\end{array}$ & $\begin{array}{l}6.6 \\
6.9 \\
7.0\end{array}$ & $\begin{array}{l}1.1 \\
1.0 \\
1.0\end{array}$ & $\begin{array}{l}1.33 \\
1.26 \\
1.17\end{array}$ & $\begin{array}{l}0.30 \\
0.29 \\
0.27\end{array}$ & $\begin{array}{l}171 \\
351 \\
313\end{array}$ & $\begin{array}{l}1.7 \\
1.8 \\
2.1\end{array}$ & $\begin{array}{l}1.4 \\
1.0 \\
1.3\end{array}$ \\
\hline \multicolumn{9}{|l|}{ Shift work } \\
\hline $\begin{array}{l}0 \text { factors present } \\
1 \text { factors present } \\
2-3 \text { factors present }\end{array}$ & $\begin{array}{l}155 \\
236 \\
274\end{array}$ & $\begin{array}{l}6.9 \\
6.8 \\
7.0\end{array}$ & $\begin{array}{l}1.1 \\
1.1 \\
1.1\end{array}$ & $\begin{array}{l}1.36 \\
1.25 \\
1.18\end{array}$ & $\begin{array}{l}0.34 \\
0.29 \\
0.28\end{array}$ & $\begin{array}{l}100 \\
173 \\
215\end{array}$ & $\begin{array}{l}1.6 \\
1.8 \\
2.2\end{array}$ & $\begin{array}{l}0.7 \\
1.0 \\
1.4\end{array}$ \\
\hline
\end{tabular}

a The triglyceride measurements were available only for the intervention group.

to correct for its bad fit. The statistical interaction was thus a purely technical, model-dependent construct, not to be confused with the notion of biological interaction (22). Unfortunately, the tests designed to help decide whether or not the interaction term was needed have very little power and are not useful without abundant data (22, 23).

The method we used is one way to proceed when joint effects are studied. First, we showed the crude incidences of CHD by combinations of risk factor levels (without any assumptions). Second, in order to adjust for covariates, the modeling was performed so that a new variable representing the combinations of the risk factor levels was formed and used in the framework of the Cox models. By comparing the unadjusted risk estimates with those adjusted, we gained information on the importance of the covariates, and by viewing the pattern of the risk estimates, we were able to evaluate the joint effect concretely. In the case of smoking and shift work the multiplicative model would yield: $R R$ (smoking only) $\times R R$ (shift work only) $=1.61 \times 1.34=2.16$, and the additive model would yield: RR (smoking only) + RR (shift work only) $-1=1.61+1.34-1=1.95$, while the true joint RR was 2.69 with confidence limits of 1.76 and 4.12. According to Saracci (7) we would conclude that the effect is nearly multiplicative. As the interaction term of smoking and shift work did not reach statistical significance, we would - this time - come to the same conclusion using formal statistical reasoning. In the case of body mass index, similar calculations would lead to the conclusion that the effect of shift work and obesity on CHD risk is at least multiplicative.

\section{Possible pathways for the effect}

The effect of smoking on CHD risk is mediated through several mechanisms. First, smoking has a long-term effect on the development of atherosclerosis, as autopsy studies have shown that smokers have more atheroma- tous plaques in coronary vessels than nonsmokers $(9,24)$. The underlying mechanisms of this phenomenon are not definitively known, but both nicotine and carbon monoxide may promote injury of the coronary artery endothelium and thus make it vulnerable to plaque formation (9). Smoking may also lower defense mechanisms and maintain chronic infections that contribute to plaque formation (25). It may promote the development of insulin resistance (26), with accompanying unfavorable lipid profile (15), or possibly also directly reduce the level of HDL cholesterol (27). Second, in addition to these long-term effects, smoking may act as a short-term trigger in the infarction process by increasing platelet aggregability and fibrinogen levels and enhancing the formation of intracoronary thromboses (10). The effects of obesity on CHD risk are also mediated through different pathways, one being the promotion of the development of the insulin resistance syndrome with high triglyceride levels and low levels of HDL cholesterol $(15,28)$ and another being the influence of the hemostatic functions, especially by decreasing fibrinolysis, either directly or via increased triglyceride levels (29). The effect of little physical activity is parallel with that of obesity in that both exert an unfavorable effect on the lipid profile and on fibrinolytic activity predisposing to thrombosis and increased CHD risk $(30,31)$. The unfavorable effect on the lipid profile was clearly seen in our study, as increased numbers of adverse life-style factors entailed considerable changes in the triglyceride and HDL cholesterol levels (table 4).

While life-style factors may promote the atherogenic processes via multiple mechanisms, it is possible that shift work contributes to several of the mechanisms. Shift workers commonly complain about fatigue and sleep loss, especially during night shifts (32). On the other hand, fatigue and sleep loss may entail a decreased immune response, and shift work may so accelerate the infection-smoking-CHD sequelae $(25,33)$. Furthermore, most metabolic processes, fibrinolysis included, follow 
a circadian rhythm, while shift work has been shown to desynchronize the circadian pattern (34). Especially fibrinolytic activity is greatly reduced during early morning hours in relation to increased plasminogen activator inhibition (35). It can be speculated that work during night shifts, with greatly decreased fibrinolytic activity or the desynchronization of the whole cardiovascular circadian system, could, in the long run, lead to increased plaque formation. Decreased fibrinolysis is also of great interest in relation to the well-established early-morning peak of different CHD events (35). Nearly half of the study participants were being treated with gemfibrozil, a drug that, in addition to its effect on serum lipids, influences fibrinolysis (36). According to our previous study, shift workers benefit more from treatment with gemfibrozil than day workers do although their mean lipid levels do not essentially differ from those of day workers (4). This finding adds some support for the hypothesis that shift work may aggravate the adverse effects of lifestyle factors on fibrinolytic activity and therefore increase CHD risk.

A hormonal pathway from shift work to increased CHD risk is also a plausible possibility. Most physiological functions follow a circadian pattern, and, especially in cases of rapidly rotating 3-shift work, desynchronization occurs $(37,38)$. This desynchronization may involve similar pituitary and adrenocortical responses such as vital exhaustion (ie, an increase in cortisol secretion with accompanying deterioration of some CHD risk factors) (39).

Another putative pathway through which shift work can increase CHD risk due to adverse life-style could be job stress. Stress-related persistent fatigue has been found to decrease fibrinolytic capacity (40) and predispose to thrombosis - in much the same way as adverse life-style factors do.

The history of research on shift work and coronary heart disease has shown that it is difficult to assess the risk from shift work properly, mainly due to problems with separating the effect of shift work from the effects of other confounding or intervening factors. It is also difficult to maintain a proper study design, as people keep moving from the shiftwork risk group into the daywork reference group. One further reason for the difficulties in assessing the risk could be that, in addition to having an "independent" effect, shift work magnifies and aggravates the effects of other noxious agents or occupational or life-style factors. The observed effect would thus depend on various other, possibly as yet unmeasured, factors, and this possibility could add extra variability and uncertainty to the measurement.

In conclusion, shift work seems to trigger the effects of other, lifestyle-related risk factors of CHD. Whatever the pathways for this effect, it calls for preventive measures in everyday health care work.

\section{Acknowledgments}

We are grateful to the Finnish Work Environment Fund for its financial support of this study.

\section{References}

1. Harrington JM. Shiftwork and health: a critical review of the literature. London: Her Majesty's Stationery Office, 1978.

2. Knutsson A, Åkerstedt T, Johnsson B, Orth-Gomer K. Increased risk of ischemic heart disease in shift workers. Lancet 1986;2:89-92.

3. Kawachi I, Colditz G, Stampfer M, Willett WC, Manson JE, Speizer FE, et al. Prospective study of shift work and risk of coronary heart disease in women. Circulation 1995;9:21-5.

4. Tenkanen L, Sjöblom T, Kalimo R, Alikoski T, Härmä M. Shift work, occupation and coronary heart disease over 6 years of follow-up in the Helsinki Heart Study. Scand J Work Environ Health 1997;23:257-65.

5. Åkerstedt T, Knutsson A. Cardiovascular disease and shift work [editorial]. Scand J Work Environ Health 1997;23:241— 2.

6. Fox AJ, Adelstein AM. Occupational mortality: work or way of life? J Epidemiol Community Health 1978;32:73-8.

7. Saracci R. The interactions of tobacco smoking and other agents in cancer etiology. Epidemiol Rev 1987;9:175—93.

8. Levy D, Kannel WB. Cardiovascular risks: new insights from Framingham. Am Heart J 1988;166:266-72.

9. Office on Smoking and Health. The health consequences of smoking: cardiovascular disease, a report of the Surgeon General. Washinton (DC): US Government Printing Office, 1983.

10. Kannel WB, D'Agostino RB, Belanger AJ. Fibrinogen, cigarette smoking and risk of cardiovascular disease: insights from the Framingham Study. Am Heart J 1987;113:100610.

11. Pekkanen J, Marti B, Nissinen A, Tuomilehto J, Punsar S, Karvonen MJ. Reduction of premature mortality by high physical activity: a 20-year follow-up of middle-aged Finnish men. Lancet 1987;2:1473-7.

12. Berlin JA, Colditz GA. A meta-analysis of physical activity in the prevention of coronary heart disease. Am $\mathrm{J}$ Epidemiol 1990;132:612-28.

13. Lakka TA, Venäläinen JM, Rauramaa R, Salonen R, Tuomilehto J, Salonen JT. Relation of leisure-time physical activity and cardiorespiratory fitness to the risk of acute myocardial infarction in men. N Engl J Med 1994;330:1549—54.

14. Modan M, Halkin A, Almog S, Lusky A, Eskol A, Shefi M, et al. Hyperinsulinemia: a link between hypertension, obesity and glucose intolerance. J Clin Invest 1985;75:809-17.

15. Reaven GM. Banting Lecture 1988: role of insulin resistance in human disease. Diabetes 1988;37:1595-607.

16. Defronzo RA, Ferrannini MD. Insulin resistance: a multifaceted syndrome responsible for NIDDM, obesity, hypertension, dyslipidemia, and atherosclerotic cardiovascular disease. Diabetes Care 1991;14:173-94.

17. Meade TW, Chakrabarti R, Haines AP, North WR, Stirling Y. Characteristics affecting fibrinolytic activity and plasma fibrinogen concentrations. BMJ 1979;1:153-6.

18. Frick MH, Elo O, Haapa K, Heinonen OP, Heinsalmi P, Helo $P$, et al. The Helsinki Heart Study: primary prevention trial 
with gemfibrozil middle-aged men with dyslipidemia: safety of treatment, changes in risk factors, and incidence of coronary heart disease. N Engl J Med 1987;317:1237-45.

19. Palomäki P, Miettinen H, Mustaniemi H, Lehto S, Pyöräłä K, Mähönen $M$, et al. Diagnosis of acute myocardial infarction by MONICA and FINMONICA diagnostic criteria in comparison with hospital discharge diagnosis. J Clin Epidemiol 1994:47:659-66.

20. Pietilä $K$, Tenkanen L, Mänttäri M, Manninen V. How to define coronary heart disease in register based follow-up studies? experience from the Helsinki Heart Study. Ann Med 1997;29:253-9.

21. Wilhelmsen L, Tibblin G, Fodor J, Werkö LA. Multifactorial primary prevention trial in Gothenburg, Sweden. In: Larsen OA, Malmberg RO, editors. Coronary heart disease and physical fitness. Copenhagen: Munksgaard, 1971:267-70.

22. Breslow NE, Day NE. Statistical methods in cancer research, vol II: the design and analysis of cohort studies. Lyon: International Agency for Research on Cancer (IARC), 1987. IARC scientific publication, no 82 .

23. Greenland S. Tests for interaction in epidemiological studies: a review and study of power. Stat Med 1983;2:243—51.

24. Auerbach O, Hammond EC, Garfinkel L. Smoking in relation to atherosclerosis of the coronary arteries. $\mathrm{N}$ Engl J Med 1965;273:775-9.

25. Hahn DL. Chlamydia, smoking and heart disease. Ann Intern Med 1992;116:171-9.

26. Facchini FS, Hollenbeck CB, Jeppesen J, Chen Y-DI, Reaven GM. Insulin resistance and cigarette smoking. Lancet 1992;339:1128 - 30.

27. Wilson PWF, Garrison RJ, Abbott RD, Castelli WP. Factors associated with lipoprotein cholesterol levels: the Framingham Study. Arteriosclerosis 1983;3:273-81.

28. Pouliot M-C, Després J-P, Nadeau A, Moorjani S, Prud'Homme D, Lupien PJ, et al. Visceral obesity in men: associations with glucose, plasma insulin, and lipoprotein levels. Diabetes 1992;41:826-34.

29. Juhan-Vague I, Vague P, Alessi MC, Badier C, Valadier Aillaud MF, Atlan C. Relationships between plasma insulin, triglyceride, body mass index, and plasminogen activator in- hibitor 1. Diabetes Metab 1987;13:331-6.

30. Barnard RJ, Ugianskis EJ, Martin DA, Inkeles SB. Role of diet and exercise in the management of hyperinsulinemia and associated atherosclerotic risk factors. Am J Cardiol 1992; 69:440-4

31. Nordoy A. Haemostatic factors in coronary heart disease. J Intern Med 1993;233:377-83

32. Frese $M$, Harwich $C$. Shiftwork and the length and quality of sleep. J Occup Med 1984;26:561 -6.

33. Saikku P, Leinonen M, Tenkanen L, Linnanmäki E, Ekman M-R, Maminen V, et al. Chronic Chlamydia pneumoniae infection as a risk factor for coronary heart disease in the Helsinki Heart Study. Ann Intern Med 1992;116:273-8.

34. Andreotti $F$, Kluft $C$. Circadian variation of fibrinolytic activity in blood. Chronobiol Int 1991;8:336-51.

35. Andreotti F, Davies GJ, Hackett DR, Khan MI. Major circadian fluctuations in fibrinolytic factors and possible relevance to time of onset of myocardial infarction, sudden cardian death and stroke. Am J Cardiol 1988;62:635-7.

36. Fujii S, Sobel BE. Direct effects of gemfibrozil on the fibrinolytic system: diminution of synthesis of plasminogen activator inhibitor type 1. Circulation 1992;85:1888-93.

37. Åkerstedt T. Psychological and psychophysiological effects of shift work. Scand J Work Environ Health 1990;16 suppl 1:67-73.

38. Torsvall L, Åkerstedt T, Gillberg M. Age, sleep and irregular work hours: a field study with electroencephalographic recordings, catecholamine excretion, and self-ratings. Scand J Environ Health 1981;7:196-203.

39. Keltikangas-Järvinen L, Räikkönen K, Hautanen A, Adlercreutz $\mathrm{H}$. Vital exhaustion, anger expression, and pituitary and adrenocortical hormones: implications for the insulin resistance syndrome. Arterioscler Thromb Vasc Biol 1996;16:275-80.

40. Räikkönen K, Lassila R, Keltikangas-Järvinen L, Hautanen A. Association of chronic stress with plasminogen activator inhibitor-1 in healthy middle-aged mean. Arterioscler Thromb 1996;16:363-7.

Received for publication: 15 October 1997 